heart disease arising from rheumatic fever to which we are bound to come is not on the same hopeful lines as is taberculosis. In this latter affection we know the problem, our information is exact, we understand what is to be done, and we can say with confidence that if the nation were to adopt the necessary messures tuberculosis would disappear; but the task is so stupendous that only by slow degrees can any improvement come; a complete radical attempt would induce a revolution. In rheumatic fever our knowledge is inexact, incomplete, perhaps even misleading. The individual may receive the advice to avoid chills, wettings, exposure, overexertion. Such advice to the nation means a higher civilization. Pare clinical study has had its innings. We must await with reverence the work of the laboratory clinician and vivisectionist.

3. The third group I shall mention is a somewhat vague bat still a very real one. It inclades that form of heart trouble due not infrequently to exertion undertaken while out of training, or immediately after a full meal under the popular idea that it was "working it down"; or while resovering from some of the minor infections, such as influenza, common cold, where the heart muscle was still suffering from the toxin; or in chlorosis, as a chlorotic girl's first day on the links in spring. Sometimes permanent dilatation and incompetency is left, even leading years afterwards to sudden death. In this type we cannot hope for much prevention-so much depends on the in. telligence and education of the patients themselves-bat ts increased recognition, both by the community and by the profession, would undoubtedly lessen its incidence.

4. We now come to the great group of the degenerations. It would be useless to speak separately of angina pectoris, of fatty degeneration, of arterio-sclerosis, of atheroma, of valvalar thickenings and degenerations. Our knowledge of the broad natural history of these affections is exten. sive, but it has not told us yet why better rubber is pat in one person's arteries than in another's, and why the webbing of the aortic valves in one person is less easily and less early irritated and degenerated than in another. We can, however, mention some causes that undoubtedly induce early degeneration, and affirm that a legitimate hope exists that these causes are being, and can be still further, lessened.

(1) Alcoholism. Heart trouble arises both from exces. sive consumption of beer-Manich heart, Tübingen heart, draymen's heart-and also from the toxic effect of the alcohol alone, as in whisky drinkers. Now the nation's bill for alcohol has fallen steadily from $£ 185,927,227$ in 1899 to $£ 161,060,482$ in 1908. Again, Horsley and Sturge's diagrams of the relative consumption of alcohol and of milk in seren of the large London hospitals point to a very decided diminution in the use of alcohol as a medicament; and lastly, a chart giving the amount of alcohol por 100 patients in the old General Hospital, Belfast, from 1851 to 1858 , with the mortality of the medical patients, and the same curves for fifty years later (1901 to 1908), demonstrating a greatly reduced alcoholic bill and a lower mortality.

Bat it is not so much the question of pure alcoholism as of alcoholism combined with physical strain, such as we see typified in soldier and shipwright. Nothing seems to bring degeneration to heart and blood vessel so early and so hopelessly as excessive physical exertion, while the system is still poisoned with alcohol and the arterioles are still dilated, allowing a runaway heart to expend itself against an unprotected capillary. Hope here lies in a higher civilization and better education, "when the citizen will be taught the rules of the game of life. Under this heading we may well include overeating, and the undue nervous strain of the day so fertile in worn-out hearts.

(2) The next cause is syphilie, bat its injarious effects axe chiefly felt in the vessel, not in the heart. However, such effect as it has we have legitimate hope of lesseningfirst, by the adoption of preventive measures, such as we see succeed in the navy; secondly, by the power of aborting the disease by Ehrlich's new remedy; and, thirdly, by the slower development of a higher civilization.

Prevention of heart disease thus embraces (1) more accurate registration of deaths, so that the huge group labelled "syncope" may be anslysed; (2) the labours of the clinical bacteriologist to teach us what is rheumatic fever and how we may prevent it ; and (3) lastly, a spread of real knowledge and education, so that men may learn not to treat their heart and blood vessels as a careless and reckless schoolboy treats his bicycle, but as a skilled engineer treats a strong yet delicately balanced piece of complicated mechanism that reacts quickly, silently, mysteriously to every touch of the skilled hand.

\section{THE TREATMENT OF RODENT ULCER.}

BY

E. GRAHAM LITTLE, M.D., F.R.C.P.LOND,

PHYSICIAN IN CHARGE OF THE SKIN DEPARTMENTS AT ST. MARY'S HOSPITAL, AND THE EAST LONDON HOSPITAL FOR

THE treatment of rodent ulcer has undergone very marked changes in the past decade, and it is probable that com. paratively fow cases are now treated surgically as compared with even as short a period as ten years ago. $A s$ a consequence of the newer physical methods of dealing with this disease, which are much less terrifying to the average lay mind than a surgical operation, the treatment is usually now commenced at an earlier stage, and one seldom sees the ghastly matilations which were not in. frequent when surgery was the only effective means, and when, therefore, patients often preferred to let the disease take its couree. This was not surprising, inasmuch as rodent alcer most commonly appears on prominent parts of the face, where the scarring from operation, which was neces. sarily widely beyond the limits of obvious disease, caused great and often hideous deformity.

\section{Treatment by Carbon Dioxide Snow.}

I have had an opportunity of testing the application of carbon dioxide snow, and of ionization, in a series of cases of rodent ulcer, both in hospital and private practice, and am mach pleased with the resalts. With the exception of a short preliminary note on this treatment by freezing of three cases of rodent ulcer by Morton, I have not seen any record of the use of this method for rodent ulcer, and my personal experience, which dates from July 14th, when I treated my first case, recorded below, may be encouraging to othere.

\section{Preparation of Carbon Dioxide Sncw.}

So many methods have been described that I should perhaps apologize for including details of the procedure I adopt. As, however, I have found that medical prac. titioners still meet with difficulties in its preparation and use, I may be pardoned for making the following preliminary remarke.

Carbon dioxide gas can be obtained readily enough from various manufacturers, its use being widespread for producing soda water. Large or small cylinders can be obtained. To the vent of the cylinder I have had fitted a small brass nozzle, about 2 in. long, which makes an adaptable support for whatever device is used to collect the snow. The quickest, most economical and satisfactory method I have found to be the blotting paper mould introduced by. Tousey. ${ }^{2}$ A rather thick blotting paper or filter paper is used; a piece about 6 in. aquare is taken, and rolled round a thick pencil or rod of the same calibre as the free end of the brass nozzle. One end of the roll of paper so formed is folded so as to produce complete obstruction, and the roll is then bandaged closely over, leaving two free ends of bandage, with which the roll is eventually attached to the neck of the cylinder. The bandaged roll is then slid on to the nozzle and tied tightly over it and round the cylinder; the stopcock is slowly turned on, until the nozzle is qoite cold and covered with frost, when, with a few more sharp tarns, the gas is released under greater pressure, and the roll can be felt to harden under the finger. The cylinder should always be supported with the neck lower than the base while the snow. is being collected. When the desired quantity has been obtained the stopcock is tarned off, and the roll, filled with hard snow, is removed and the bandages and blotting paper peeled off, expcsing a stick about the size and thickness of the little finger. For many purposes this is sufficiently compressed, but for rodent ulcers, where 
much presurive should bo exercised, it will require grester density. To effect this the stiok is intreduced bodily into a haxdwood mould with a well fitting wooden planger.* The stiok is then broken up inside the mould by a series of shaip taps with the plunger, and then rammed down by striking the plunger with a wooden mallet. A stick about an inch long and hard enough to trim and out to any desired smaller size or shape is thas usually obtsined. In order to handle this without risk to the operator several folds of cotton-wool should intervene between the stick and the hand; the free end, uncovered by wool, is applied direotly to the part to be treated.

I have, I believe, found it asetul to prepare the surface by making the patient wear over the part for three or four days prior to the freezing a salicylic acid plaster (25 per cent.). If there is much scabbing, it is best to remove the scab (which the plaster effects), and to have a clean area to treat. Bleeding may be checked by swabbing the surface with adrenalin, but the freezing will usually have this effect by itself.

The pressure to be used and the duration of the application will depend on the thickness of the skin and the depth of ulceration. My arerage time has been twenty to twenty-five seconds, and the pressure as firm as the patient can stand. Where the alcer is situated directly over bone, the pressure can be very firm, and the time may be shortened; in positions where there is less resistance to the touch the time will require to be longer.

No pain worth troubling about is felt during the application; the pressure exerted, indeed, seems to be the part of the procedure most disliked by the patient. In a few minutes, however, after thawing, the smarting commences, and may persist for a couple of hours; its duration and degree may, perhaps, be shortened by the application of warm compresses immediately after the freezing.

When the operation has been properly performed, the ulcerated or infiltrated area is entirely swallowed up in the depressed cup in the skin produced by freezing, which should extend beyond the actual seat of diserse by about one-eighth of an inch. Occasionally, when the ulcer is on a part of the integument with much subcutaneous cellular tissue, there will be considerable oedema and disfigurement, since the eje and nose are usually near neighbours of the lesions. Patients should be warned of this, and that it is quite unimportant. The treatment of the part atter freezing consists in applying either lotions or ointments; the former if there is much oedema, the latter if there is not. Saturated boracic fomentations or boracic ointment may thus be used. One application of freezing for twenty seconds may be sufficient, but much more commonly two or three or more will be required, and these are best given at intervals of about a week. The indication for cessing treatment is found in the disappearance of the hard cartilage-like tissue characteristic of rodent, and the closure of the ulceration. The scar is surprisingly inconspicuous and like natural skin. I heve repeatedly invited a large class of students to identify the site of an ulcer thus treated, three months after treatment, and they have rarely succeeded in doing so.

\section{Treatment by Ionization.}

Freezing is so convenient of application, so painless, and so rapid that it has, to a great extent, replaced with me the procedure by ionization. This, however, may, at times, be the more convenient method for the practitioner, who will almost certainly have an active galvanic battery at hand and may not be so likely to have a cylinder of gas. It is also an alternative which may actually be preferred, as it certainly produces less immediate disfigurement and, I believe, is equally efficacious, with an equally happy cosmetic result. This, at any rate, was the verdict on two cases which I showed to the Harveian Society, one treated with carbon dioxide and one with ionization (recorded below).

The method may be described briefly as follows:

A galvanic battery of 20 to 30 cells will be needed capable of producing 5 to 10 milliamperes of current with the patient in the circuit. Electrodes of pure zinc graduated in size to the lesion to be treated, are attached to the positive pole of the battery, and the metallic anrface covered with four to six folds of gauze, saturated with a

* Messrs. Maw and Thompson supply there in several convenient solution of zinc sulphate (2 per cent.) in distilled water The patient will hold the negative electrode, which is most conveniently cylindrical. This must also be costed with clean ganze soaked in warm saline solution. The current is turned on cell by coll until the galvanometer reads about 5 to 7 milliampères, and kept at this strength for from twenty to thirty minates (according to the thickness of the skin), and then turned off cell by cell. The application is sometimes somewhat painful, but if the precantion of gradual addition and removal of current is observed, the pain is much diminished and quite bearable. The immediate effect is a slight whitening and depression of the part treated, which soon passes off; a soab will probably form on the part some hours after and remain for a couple of days or more; treatment can be undertaken again, when necessary-usually within seven days.

Cases Treated by Ionization.

. Edward D., aged 42, sent to me by my colleague Mr. Pepper, who regarded the condition as "early rodent." The patien had had a flat, slightly pigmented, warty growth under the lef eye for twenty years; latterly it had begun to grow larger, and was beginning to be felt uncomfortably. When seen he had a flat, pigmented warty growth, about 3 in. by 1 in., with no symptoms of ulceration, but the history of incresse in size and

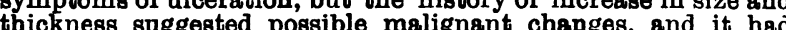
been proposed to excise the affected area. I suggested trying him first with ionization, and this course was agreed upon. caused the patient to wear a salicylic acid plaster (25 per cent.) for a week, and then gave him two treatments of zinc ionization of twenty minutes at a time, and separated by a week. $\mathrm{He}$ came to see me a month later, and the growth had entirely disappeared, leaving a scarcely visible slight atrophy, no actual scarring. It is more than two years since the treatment. I have seen the patient again recently, and he has had no recurrence, and the site of the growth is unrecognizable except with lens.

2. Charles E., aged 63, was sent to me by Dr. Lovell for treatment of a small rodent ulcer near the.inner canthus of the left eye, about $\frac{1}{2}$ in. in diameter, ulcerated and excavated. He had had this condition for several months; the earliest date of advent was not definitely known. He received two treatment of ionization in June, 1909, the first for eighteen minutes with 4 milliamperes, the second of twenty minutes with the same current. This resulted in apparently complete healing, and I did not see the patient again until a month ago, when he was again sent to me by Dr. Lovell ; he appeared to have a slightly hyper. trophic scar in the middle of the old nlceration (which was quite healed) and a doubtful recurrence of hard rodent tissue at the edges of the patch treated. My experience with carbon dioxide in hypertrophic scarring has been so good that I decided to treat the whole area, including the new dubious growth, with this agent. The result of this single application has been very satisfactory. The patient writes (November 29th): "The place is quite healed, and there is much less ridge (that is, hypertrophic scarring) than before the last treatment.

3. Thomas M. aged 40 , came to me with a small rodent ulcer on the vertical line between the inner canthus of the eye and the ala nasi on the left side. The ulcer, when first seen on February 3rd, 1910, had lasted for twelve months, and was the size of a threepenny piece. It was definitely ulcerated. He received two treatments with zinc ions, lasting for twenty minutes each, with about 5 milliampères. On March 21st there was no more rodent tissue perceptible, and there was complete hesling with the formstion of a perfect scar by April 18th. He was seen again and was shown to the Harveian Society on October 13th. There had been no recurrence, and the scar was excellent.

4. John F., aged 43, was sent to my department at St. Mary's Hospital for the first time in March, 1904, with a rodent ulcer 1 in. by in. at the lower end of the naso-labial sulcus on the left side. This had persisted for some two years before his coming to the hospital. He was treated with $x$ rays by the radiographer to the hospital, and after about sixteen exposures the growth had almost disappeared. There were recurrences, however, from time to time, and the $x$ rays, although given in full doses and very frequently (he had about seventy-five exposures), failed to effect a permanent cure. I then decided to try him with zinc ionization, and commenced this treatment in October, 1908. He had about eight treatments in all, averaging twenty flve to thirty minutes in duration, and these have resulted in an apparently complete cure. He was seen on December 5th, 1910 and the scar was perfectly continuous, with no ulceration and no rodent tissue perceptible to touch or sight. The extraordinary vitality of the malignant tissue in this case, and the comparative failure of $x$ rays after a prolonged treatment are worthy of note.

5. James M., aged 48, sent to me by Dr. Liston of Tewkesbury on November 2nd, 1908. He had had a typical rodent ulcer on the side of the nose for the previous five years, which had resisted all local treatment. He was obliged to return to Tewkesbury immediately, and I gave him accordingly a single treatment, with zinc ions, of twenty-five minutes, and sent him back the same day. I heard from the patient a month later that the ulcer had completely healed, a report confirmed by Dr. Liston. I have heard again from this patient, in response to an inquiry; he says (December 1st, 1910): "My. face is quite well ; 
in fact, you could see no sign of the ulcer three months after you trested it."

6. Mrs. H., gged 60, was sent to me by Dr. d'Esterre on March 7th, 1910, with a large rodent ulcer, and possibly an aggregation of geveral smaller rodent ulcers, on the left cheek, near the ear. She was given four treatments by zinc ionization (20 to 30 minutes), but at too remote intervals to obtain any cumalative effect. She was seen again, after a long absence, on December 5th, when some rodent tissue was still perceptible in the site treated, and this whole area was frozen anew with $\mathrm{CO}_{2}$ snow for twenty-five seconds. The ionizstion had effected an improvement considerable enough to induce the patient to cease her visits, but had not completed the removal of malignant tissue as perceptible by clinical observation.

7. Margaret L., aged now 71, was first seen by me in 1903 She had at that time a rodent ulcer, about 3 in. $x 1$ in. long, over the left eyebrow, which had been present for five years previously, and had developed on the site of a pigmented naevus. She was ordered $x$-ray trestment, which was given by the radiographer to St. Mary's Hospital. The ulcer proved singularly resistant to this treatment, and she attended off and on for five years, never getting really well, and having frequent severe conjunctivitis from the exposures to $x$ rays She had had, probably, at least 100 treatments, and had ceased pursuing these, when, in May, 1909, I decided to try zinc
ionization. She had four treatments of this, but suffered so much pain (she is a highly nervous woman) that she could not be prevailed upon to continue. Excision was accordingly recommended, and was performed in Angust, 1909, by Mr. - Olayton Greene, an excision wide of the lesion being practised. She has returned to-day (December lst) with a recurrence of rodent tissue in the terminal line of the scar of this excision. Mr. Clayton Greene, who has seen the patient, corroborates the fact of recurrence. This oase is instructive, as showing the obstinacy of some rodent ulcers to every form of trestrment, and also incidentally as showing that operation is not alway preventive of recurrence any more than other messures. I freezing (December 5th).

Cases Treated by Freezing with Carbon Dioxide Snow.

1. Mrs. T., aged 50, sent to me by Dr. Stanley Blaker of Ealing: she had had a small ulcer for two years on the right side of the nose, just above the ala nasi. This bled frequently and had a permanent and rather deep excavated centre with a typical hard edge; the whole about ${ }_{18}^{3}$ in. in diameter. It apparently began with a small scratch. She had two treatments of freezing for twenty seconds at intervals of one week, with a preliminary three days' wear of salicylic acid plaster, 25 per cent. The last treatment was in Jure; she was seen on November 20th, when the ulcer was perfectly hesled and showed no sign of recurrence.

2. Miss M., aged 64, sent to me by my colleague, Dr. W. H. Willcox, with a small circinate rodent 1 in. in diameter on the centre of the nose at the junction of bone and cartilage; the ulcer was hard and much excavated and had persisted for five jears. She had another more recent and less indurated rodent nodule on the temple. Three applications of carbon dioxide spow of twenty seconds were made to each of the lesions, and the case when seen last (October 7th) showed a nearly healed surface over both ulcers, with no rodent tissue perceptible in either. She writes (November 29th): "Both places have quite healed and are completely cured."

3. Eliza B., aged 44, was sent to me on July 14th with a rodent ulcer the size of a threepenny piece at the outer canthus of the right eye. She had had the ulcer for five to six years; it was excavated by ulceration in the usual way. She had three trestments of 20 to 25 seconds each time with carbon dioxide snow. The result was apparently perfect cure, the scar being somewhat pigmented at first, but quite devoid of any thickening or inflitration; and it has remained so up to date. She was shown at the Harveian Society on October 13th.

4. Annie H., aged 40, came to 8t. Mary's Hospital on July 21st, 1910 , having been sent on to.me by Mr. Maynard Smith. She had a rodent ulcer on the left cheek, just nnder the eye. The ulcer was rather elongated than round, and the margin was unnsually elevated and hard. It had persisted for twelve years, and hed been thought to be tuberculous, and, accordingly, the opsonic index to tubercle had been investigsted, and found to be 1.17. A nomewhat ancertain history of a congenital pigmented patch having preceded the development of the ulcer was given by the patient. She was subjected to three applications of carbon dioxide snow on July 28th, Angust 11th, and Beptember 15 th (the later interval representing the long vacstion), and on October 3rd the lesion was reported to be quite well; she was seen again on December 5th, and still showed no signs of disease or recurrence in the scar, which was so perfect as to be barely recognizable as scar tissue.

5. Helen V., aged 30, was sent to me at St. Mary's Hospital on September 29 th with a small, very vascular nodule on the upper lip just below the septum nasi. This had been present for some months, bat had begun to bleed on friction; it was thought to be probably an early rodent nodule, and as the patient was inconvenienced by it she desired its extirpation. The nodule was raised about ${ }_{13}^{3}$ in. from the surface, and was of about the same diameter. Application of carbon dioxide snow was made for 30 seconds (as the growth was so firm and solid) on the following dates-September 29th, October 6th, 13th, 20th, 27 th ; it was then left for four weeks, and a final application made on November 24th, bo which time the growth had entirely disappesred, and the surface of the site it had cocupied was quite flush with the rest of the skin.

6. Francis A., aged 68, was sent to me at 8t. Mary's Hospital on July 14th with a rodent ulcer of about a quarter of an inch in diameter, situsted quite near the right als nasi in the naso-labial sulous. He had had this ulcerstion for two years. He received four trestments of carbon dioxide freezing for periods of twenty-five seconds, the last application reezing for periods of twenty-inve seconds, the last application having been about Beptember 12th. He was seen again two stretching the skin very forcibly over the site treated, when a faint whiteness as compared with the rest of the skin conld be detected in the position of the previous lesion.

7. Annie F., aged 60, was sent to me from the eje department of St. Mary's Hospital on October 24th, when she showed a rodent ulcer sbout a quarter by half an inch in size, elongated in the transverse dismeter, and with a curiously hard ridge, sitnated on the outer side of the lower left eyelid. This had been noted for three years. She had three applications of carbon dioxide snow for twenty to twenty-five seconds at a time-on October 24 th, November 3rd, November 17 th. At the later date the rodent tissue seemed no longer present, and the ulcer at the present time (December lst) has completely healea.

8. Richard S., aged 54, has a small rodent ulcer, about $z$ in. by 1 in. just above the free edge of the right ala nasi. He had noticed this for about two years. This man had a single treatment of freezing by carbondioxide at the end of September, 1910, which in his opinion had cured him; he took French leave and remained away until summoned by me to the hospital on December 5 th, when I detected the presence of rodent tissue in the site of the

9. Henry P., agod 60, came to St. Mary's Hospital with a small early rodent nlcer on the bridge of the nose. The vicer had developed on the site of a small lesion of the type of " sebaceous epithelioma" of Besnier. He had two treatments of caxbon dioxide snow, applied for twenty seconds at a time. The last treatment was on October 20th, 1910; he was seen on December 5th, when he had a perfectly healthy and scarcely visible scar on the site treated.

10. Richard H., aged 60 , had noted a "chronic ulcer," $\frac{1}{2}$ in. long, on the right side of the nose, stretching from the inner canthus of the orbit to the bridge of the nose, for three yeantbefore his admission to the skin department at St. Mary's Hospital. He was given two treatments of twenty seconds each, the last one being in September, 1910. The ulce: "completely healed," as he thought, so that he did not return for treatment. He came to see me in response to a request to do so to-day (December 5th), and although the site of the original ulcer is patch a doubtfal ares where rodent tissue may be present, and patch a doubtfal ares where rodent tissue may be present, and that he desisted from coming without my sanction, and that $I$ was not satisfled of his cure when I had performed the second application.

11. William P., aged 72, was sent to me by Dr. John Harris on September 5th with a large epitheliomatous ulcer on the mucous membrane of the lower lip, with a foul surface and fungating growth. No enlarged glands could be felt in the neck. The ulcer had commenced to give trouble three or four months previously, and had begun in the site of a fissure. The patient was an old and feeble man, and those faots, together With the absence of enlarged glands, seemed to me to justify trying the effect of carbon dioxide snow in place of operation. My colleague, Mr. Clayton Greene, whom I asked to see the case, was strongly in favour of operating upon the lip, but eventually it was agreed that the effect of freezing should be tried. He was admitted to St. Mary's Hospital, and various parts of the ulcer, which covered an area of about $3 \times 1$ in., were exposed to freezing at intervals of about five days, each area having about three treatments. Mr. Clayton Greene saw the case a feeling of great surprise at geeing $P$. You are must confess to epithelioms is much better. I can't feel any glands, and against my former opinion I am inclined to temporize." The lesion was by this time reduced to half its size; it was no longer was by this time reduced to half its size; it was no longer
ulcerating, but had receded to a nodular swelling quite inoffensive and dry. The man was now quite set against having it removed surgicelly. He had not remained in the hospital, and had attended irregularly, so that the freezing treatment had not had as good a trial as it should have done, but it nevertheless promised astonishingly well.

I commenced this paper with the remark that one did not now see such extensive ravages in this disesse as one did ten or fifteen years ago. I was under the impression that the disease was becoming also more rare, but on comparing Dr. Radcliffe Crocker's statistics with my own, I cannot confirm this impression. In 10,000 cases of skin disease in hospital patients, Crocker recorded 14 rodent alcers (1.4 per 1,000). In examining my records at St. Mary's Hospital (April, 1903, to August, 1910), I find that out of 12,500 cases of general diseases of the skjn I had 27 cases of rodent ulcer (2.3 per 1,0C0);Crocker's statistics must have been compiled before 1893, as thay appear in this form in the second edition of his textbook published in that year. So that they represent a period earlier by at least ten years than my own (1903-1910). 
It may be objected that my repetition of applications of freezing are unnecessary, and that a longer and single exposure would be preferable. With this view I do not agree; it must never be forgotten that different persons have different degrees of cutaneous vulnerability, and that longer exposures, as advised by Morton, may in exceptional cases cause a really severe ulceration, producing scarring more disfiguring than the lesion treated. Since the disease is almost restricted to the face, the effects of disfigurement are most important to avoid, and it is batter in my opinion to do shorter treatments repeated as often as may be required. It will be seen that in the greater number of $\mathrm{my}$ cases three was the maximum number needed. In no case have I had a reaction that was resented by the patient, and I have not met with the very unsightly and alarming oedema of the solt tissue of the face which I have sometimes produced with longer exposures practised for other diseases - for example, lupus valgaris and lapus erythemstosas. With so chronic a disease as rodent ulcer, whether the daration of the treatment extends over one week or one month, is of little import.

The propriety of treating any malignant tumours without radical operations of removal may very reasonably be questioned, especially by surgeons, som $\theta$ of whom are not inclined to viow the radium propaganda with approbation. In the crise of rodent ulcers the malignancy is so slight, and the absence of glandalar invol vement so constant, the disfigarement projuced by radical removal so great, and in the special circumstances of its usual sites so resented by patients, that the decision in practical experience goes against the operating surgeon in the majority of instances, and it becomes a choice as to what other means can be adopted. The choice at present lies between (1) $x$ rays; (2) radium; (3) actual cautery; (4) ionization; (5) freezing. My experience with the $x$ ray method has been that it is more uncertain in its effects than the two methods I have adrocated above, much more tedious, more exposed to risk of untoward happenings, such as severe conjunctivitis, for the ulcer commonly is in such positions that the conjunctiva cannot help being included in the exposure, and such as disfiguring telangieotases on the parts treated.

I am aware that other observers, with far wider experience of $x$.ray treatment than I possess, still prefer this treafment to all others. Sequeira, ${ }^{3}$ who has had an exceptional opportanity of testing this therapentic agency, reported 181 cases of rodent alcer so treated; of these, 75 had remained cured for at least three years; 26 for at lesst two years; 38 had relapses, of which 31 were ulti. mately healed; and in 42 healing was not obtained by this means. Sequeira remarks that there is "a class of appar. ently slight cases which prove very resistant to $x$ rays," and it is just in these cases that I should advise the substitution of the methods of ionization and freezing.

With radium the same uncertainty exists as to what the extent of the effect may be, and treatment is tedious and exponsive, and often not within the reach of practi. tioners out of the large towns.

I have had small personal experience of the actual cautery, a treat ment much practised in Paris at present, but I have seen two excellent results. It is rapid and convenient, but produces much more scarring than either of the two processes I have described in detail.

Between ionization and freezing, which are equally convenient and widely practicable, my own preference has tarned to the latter, but I am not convinced that ionization is not equally efficient in producing a permanent cure.

\footnotetext{
1 Lancet. July 9th, 1910. 2 Journ. Amer. Med. As8oc., May 7th, 1910 Transxctions, Second Congress of International Surgical Society. Brussels, 1908.
}

WE are informed that some of the flims of microorganisms referred to in the paragraph headed "Cine. matographic Microscopy," published in the JOURNAL of December 31st, 1910, p. 2037, will be shown at a meeting of the Camera Club on January 19th at 8.30 p.m. The accommodation is limited, but any members of the Asso. ciation who desire to be present will receive invitations if they will promptly send their names to Mr. Henry W. Faitrholme, honorary secretary of the Camera Club, 17, John Street, Adelphi, W.C.

\section{EXCISION OF A CANCEROUS SEGMENT OF \\ THE OESOPHAGUS : RESTORATION OF THE OESOPHAGUS BY MEANS OF SKIN FLAP.}

By W. ARBUTHNOT LANE, M.S.,

SURGEON TO GUY'S HOSPITAL, AND TO THE HOSPITAL FOR SICK CHILDREN, GREAT ORMOND STREET.

To the general surgeon no class of case appears to be as utterly hopeless as cancer of the oesophagus. When the portion of the oesophagus within the thorax is involved the possibility of resecting a section of it by any operation however severe, and of eliminating the disease, appears to be very remote. In auch cases I think that the wisest course to pursue is to make a fistulous opening into the stomach, through which the patient can be fed easily and without discomfort. The operation is a very simple one, and it is accompanied with only a slight amount of painan important feature to a patient who is often more than half starved and whose plack is consequently destroyed. After this operative procedure has been effected satisfactorily the growth can be treated by means of radium or its emanations. A tube containing this substance can be readily introduced into and retained in the cancerous stricture for as long a period as may seem advisable. Cancer of the oesophagus offers an ideal situation for the treatment by radium, particularly as it extends so slowly by means of glandalar infection.

The cases of cancer of the oesophagus which are, perhaps, of most practical interest to the surgeon are those in which the disease affects a portion of the oesophagus in the neck. In such the surgeon occasionally performs operations of considerable magnitude, in which he generally lesves the patient in greater pain and much more uncomfortable than he was before the operation, or he opens the oesophagus below the growth, not affecting appreciably the rate of growth of the disease.

It seems to me that in most cases of cancer of the oesophagus in the neck one can follow the general principle of removing the growth in its entirety and yet leave the patient in a condition of comparative comfort after the operation.

I will now describe a case illustrating a method of treatment which is comparatively simple and not in. frequently applicable in cancer affecting the oesopbagus in the neck. Unfortunately, as the extreme upper limit of the oesophagus was involved in this particular case, the result was not as functionally perfect as it would have been if a segment of the upper portion of the normal oesophagus could have been left in which food and secretions could have collected free of the laryngeal aperture.

The principle of the operation is to excise the portion of the oesophagus affected by cancer together with any glands, keeping well away from the diseased area, and to replace the segment of oesophagus removed by means of a strip of skin cut transversely from the neck, and retaining an attachment and blood supply, the continuity of the oesophagus being completely restored. After an interval of sufficient length for the firm union of the skin oesophagus to the portion of the normal oesophagus at the lines of section, the attachment of the flap of skin by its base to the skin of the neck is divided, and any lateral apertare in the skin oesophagus which may remain is closed. Except when the growth involves the extreme upper limit of the oesophagus or invades the upper aperture of the larynx it would probably be possible to avoid performing tracheotomy. Till the edges of the skin oesophagas have united to those of the oesophagus, a tube for feeding purposes should be retained in position.

A. W., 30, married, came under my care on May 10 th, 1909. She had for four months experienced increasing difficulty in swallowing, and this had progressed until ohe was only able to swallow a few drops of water. In consequence of this prolonged starvation she was very emaciated and feeble. She had a carcinoma of the upper limit of the oesophagus, which appeared to invade the back of the arytenoid muscle. Mr. Charters Symonds, whose experience of cancer of the oesophagas is probably unrivalled in England, confirmed my diagnosis. A fine 